\title{
Role of the PI3K-mTOR autophagy pathway in nerve damage in rats with intermittent hypoxia-aggravated whole brain ischemia
}

\author{
XIA GUO $^{1}$, YAO LIU $^{2}$, YANING ZHAO ${ }^{2}$, RONG FAN ${ }^{2}$, YALI BAI ${ }^{2}$, \\ XIANGFEI GUO ${ }^{2}$, JIANMIN LI $^{1}$ and CHANGXIANG CHEN ${ }^{2}$ \\ ${ }^{1}$ Department of Respiratory Medicine, Affiliated Hospital of North China University of Science and Technology; \\ ${ }^{2}$ Department of Rehabilitation, College of Nursing and Rehabilitation, \\ North China University of Science and Technology, Tangshan, Hebei 063000, P.R. China
}

Received April 13, 2016; Accepted March 28, 2017

DOI: $10.3892 / \mathrm{mmr} .2019 .10337$

\begin{abstract}
The present study aimed to compare the expression of phosphatidylinositol 3-kinase (PI3-K), mammalian target of rapamycin (mTOR) and Beclin-1 between the hippocampi of normal rats and intermittent ischemic rats following whole brain ischemia/reperfusion (I/R), and investigate the role of the PI3K-mTOR autophagy pathway in rat nerve damage following intermittent hypoxia (IH)-aggravated whole brain ischemia. A total of 80 male Wistar rats were divided by random number table into a sham operation group (SO group; 20 rats), pure cerebral ischemia/reperfusion group (I/R group; 20 rats), intermittent hypoxia for 7 days-I/R group (IH7+I/R group; 20 rats) and intermittent hypoxia for 21 days-IR group (IH21+I/R group; 20 rats). Prior to model establishment, the rats in the $\mathrm{IH} 7+\mathrm{I} / \mathrm{R}$ group and $\mathrm{IH} 21+\mathrm{I} / \mathrm{R}$ group underwent intermittent hypoxia for 7 and 21 days, respectively. The optimized Pulsinelli 4-vessel occlusion method was used to prepare the I/R model. H\&E staining and transmission electron microscopy were performed to observe the morphological changes of nerve cells in the hippocampus. Immunohistochemical and reverse transcription-quantitative polymerase chain reaction (RT-qPCR) analyses were performed to detect the expression levels of PI3-K, mTOR and Beclin-1 in the hippocampal brain tissues of the rats. A Morris water maze test was used to assess rat learning and memory. The results showed that, compared with the SO group, the rats in the I/R group exhibited structural damage in neurons (shown by H\&E staining), a reduced number of viable nerve cells, and decreased learning and memory ability at each time point. The results of the immunohistochemical analysis showed that the numbers of PI3-K,
\end{abstract}

Correspondence to: Dr Yaning Zhao, Department of Rehabilitation, College of Nursing and Rehabilitation, North China University of Science and Technology, 21 Bohai Avenue, Caofeidian New City, Tangshan, Hebei 063000, P.R. China

E-mail: zyning789@126.com

Key words: intermittent hypoxia, cerebral ischemia and reperfusion, phosphatidylinositol 3-kinase, mammalian target of rapamycin, autophagy
mTOR and Beclin-1 immunopositive cells were increased $(\mathrm{P}<0.05)$. The RT-qPCR analysis showed increased expression levels of PI3-K, mTOR and Beclin-1 $(\mathrm{P}<0.05)$. Compared with the I/R group, the rats in the IH-I/R groups exhibited aggravated structural damage in neurons, shown by H\&E staining and electron microscopy. The number of viable nerve cells was decreased, and the rats exhibited decreased learning ability and memory. The immunohistochemical analysis revealed that the numbers of PI3-K, mTOR and Beclin-1 immunopositive cells were increased $(\mathrm{P}<0.05)$. The RT-qPCR analysis showed increased expression levels of PI3-K, mTOR and Beclin-1 $(\mathrm{P}<0.05)$. The above changes were more marked in the $\mathrm{IH} 21+\mathrm{I} / \mathrm{R}$ group $(\mathrm{P}<0.05)$. Taken together, $\mathrm{IH}$ was shown to aggravate nerve damage following whole brain I/R. The underlying mechanism was associated with activation of the PI3K-mTOR-autophagy pathway and increased loss of nerve cells.

\section{Introduction}

Obstructive sleep apnea hypopnea syndrome (OSAHS) can aggravate the nerve damage caused by brain ischemia, which is an independent risk factor increasing the morbidity and mortality rates of ischemic stroke $(1,2)$. It has been shown that cognitive dysfunction following brain ischemia is closely associated with cellular metabolic changes, signal transduction system disorder and nerve cell death following brain tissue ischemia and hypoxia $(3,4)$. Autophagy, a cellular defense mechanism of eukaryotic cells, is essential in maintaining intracellular homeostasis, and determines the final outcome of cells: Recovery, repair, damage, aggravation or death (5). The phosphatidylinositol 3-kinase (PI3K)/protein kinase B (Akt)/mammalian target of rapamycin (mTOR) classic cascade signaling pathway effectively regulates multiple physiological and pathological mechanisms, is involved in various eukaryotic processes, including autophagy, proliferation and apoptosis, and is important in diseases of the central nervous system (6,7). Following OSAHS-complicated ischemic stroke, a variety of factors are aggravated, including oxygen free radicals, oxidative stress and inflammatory reactions. These factors can cause increased nerve cell death, either directly or indirectly. Therefore, the present study hypothesized that 
the PI3K-mTOR autophagy pathway is important in the pathological progress of nerve damage following intermittent hypoxia (IH)-aggravated brain ischemia. In the present study, the whole brain ischemia/reperfusion (I/R) model was prepared using rats exposed to intermittent hypoxia. Expression of the PI3K-mTOR autophagy pathway and loss of nerve cells in the hippocampus were observed. The role of the PI3K-mTOR autophagy pathway in IH-aggravated brain I/R was investigated and discussed. The results provided experimental evidence for the clinical prevention and treatment of OSAHS complicated by hypoxic brain vascular diseases.

\section{Materials and methods}

Materials. Male Wistar rats $(\mathrm{n}=80)$ were provided by Vital River Laboratories Co., Ltd. (Beijing, China). The certificate number for the laboratory animals was SCXK (Jing) 2012-013. Animals were kept in colony cages; under the following laboratory conditions in a ventilated room: $18-25^{\circ} \mathrm{C}, 35-50 \%$ humidity and a $12 \mathrm{~h}$ light dark cycle, with free access to food and water. The present study was performed with approval from the Animals Welfare Care Committee of North China University of Science and Technology (Tangshan, China). The hypoxia control program was provided by the Science and Technology Center of Tsinghua University (Beijing, China). Oxygen measurement equipment was purchased from Jiande Meicheng Electrochemical Analytical Instrument Factory (Jiande, China). The animal hypoxia chamber was purchased from China Huaibei Zhenghua Science and Technology Co., Ltd. (Huaibei, China). Pure nitrogen was purchased from Tangshan General Gas High-Tech Co., Ltd. (Tangshan, China). The Morris water maze was provided by the Pharmaceutical Research Institute of China Academy of Medical Sciences (Beijing, China).

Groups of animals and model preparation. The rats were divided by random number table into a sham operation (SO) group ( $\mathrm{n}=20), \mathrm{I} / \mathrm{R}$ group $(\mathrm{n}=20)$, IH for 7 days (IH7)+I/R group $(n=20)$ and $I H$ for 21 days $(I H 21)+I / R$ group $(n=20)$. Each group was further divided into a 6 and $24 \mathrm{~h}$ subgroup, with 10 rats in each subgroup.

The blood vessels in the rats of the SO group were separated and exposed. Electrocoagulation of the vertebral artery and occlusion of the carotid artery were not performed. For the rats in the $\mathrm{I} / \mathrm{R}, \mathrm{IH} 7+\mathrm{I} / \mathrm{R}$ and $\mathrm{IH} 21+\mathrm{I} / \mathrm{R}$ groups, the whole brain ischemia model was prepared using the optimized Pulsinelli 4-vessel occlusion method (8). Anesthesia was induced by intraperitoneal injection of $10 \%$ chloral hydrate at a dose of $300 \mathrm{mg} / \mathrm{kg}$, (Sigma-Aldrich; Merck KGaA, Darmstadt, Germany). An incision was made in the rear occipital and the holes on the bilateral flank were carefully exposed. The pre-heated electrocoagulation needle was inserted and electrocoagulation was performed for 2-4 sec each time to occlude the bilateral vertebral artery. The rats were fixed in a supine position on the surgical bench and an incision was made in the middle of the neck to separate the common carotid arteries on both sides. After $24 \mathrm{~h}$, the bilateral common carotid arteries were occluded at the same time for $15 \mathrm{~min}$ to achieve complete whole brain ischemia.

The rats in the $\mathrm{IH} 7+\mathrm{I} / \mathrm{R}$ and $\mathrm{IH} 21+\mathrm{I} / \mathrm{R}$ groups were placed in a hypoxia chamber every day from 8:00 a.m. to 15:00 p.m. Nitrogen and air were introduced into the chamber recurrently.
Each cycle lasted for $120 \mathrm{sec}$ and nitrogen was added continuously for $30 \mathrm{sec}$ to maintain an oxygen level of 5-21\% in the chamber. The oxygen concentration was monitored using a digital oxygen analyzer for 7 and 21 days, respectively.

$H \& E$ staining. A total of five rats were randomly selected from each group at 6 and $24 \mathrm{~h}$ post-I/R, respectively. Cardiac perfusion was performed using $4 \%$ paraformaldehyde. The rats were sacrificed and, following decapitation, brain tissue was removed. The tissue between the optic chiasm plane and transverse section was dehydrated, embedded in paraffin, sectioned, dewaxed, cleared in xylene, stained with H\&E and observed under a light microscope (magnification, $\mathrm{x} 400$ ).

Observation using transmission electron microscopy. Five rats were randomly selected from each group at 6 and $24 \mathrm{~h}$ post-I/R, respectively. The hippocampal tissue from these animals was removed, sectioned into $1 \mathrm{~mm}^{3}$ tissue blocks, fixed in $40 \mathrm{ml} / 1$ glutaraldehyde, rinsed twice in $0.1 \mathrm{~mol} / 1$ cacodylate acid buffer, fixed in $10 \mathrm{~g} / 1$ osmium tetroxide, rinsed twice with buffer and placed at $4^{\circ} \mathrm{C}$ overnight. The tissues were dehydrated using an acetone concentration gradient, embedded in epoxy resin, sectioned into 40-50 $\mathrm{nm}$ ultra-thin slides, double stained with uranyl acetate and lead citrate, and observed under an electron microscope.

Immunohistochemical staining. The brain tissue slides were subjected to conventional dewaxing to water, blocking in $0.3 \% \mathrm{H}_{2} \mathrm{O}_{2}$ for $10 \mathrm{~min}$ and heated antigen retrieval for $90 \mathrm{sec}$. Antibodies against PI3-K, mTOR and Beclin-1 were added onto the slides, respectively, and the slides were incubated in a humid box at $37^{\circ} \mathrm{C}$ for $30 \mathrm{~min}$. The secondary antibody was added and the slides were incubated at $37^{\circ} \mathrm{C}$ for $40 \mathrm{~min}$. Mouse monoclonal anti-PI3-K (1:200, Bioss, Product batch number: bs-0128R); Mouse monoclonal anti-mTOR (1:150, Bioss, Beijing, China, Product batch number: bs-5331R); Mouse monoclonal anti-Beclin-1 (1:200, Baomanbio, Shanghai, China, Product batch number: OSA00006W). The slides were then subjected to DAB development, dehydration, clearing, neutral resin-mounting and microscope observation. Quantitative analysis of the positive rate was performed using the following method. A total of five slides were selected from each parameter, and five regions in the hippocampus were randomly selected in each slide under a light microscope (magnification, $\mathrm{x} 400$ ). The number of positive cells was counted using a FACS-like tissue cytometry analysis system (Tissue FAXS plus, TissueGnostics GmbH, Vienna, Austria).

$R T-q P C R$ analysis. Five rats were randomly selected from each group at 6 and $24 \mathrm{~h}$ post-I/R, respectively. A $50-100 \mathrm{mg}$ sample of tissue from the CA1 region of rat the hippocampus was collected and homogenized in TRIzol solution. Total RNA was extracted. cDNA samples were blended with DEPC-treated Water and SYBR-Green Master Mix in a total volume of $20 \mu \mathrm{l}$. The OD260/280 was measured using a Roter-Gene 3000 Fluorescence quantitative PCR instrument. The RNA concentrations were calculated based on the OD260 and the RNA samples were stored at $-80^{\circ} \mathrm{C}$. The following primers were used: PI3K, forward GAAACCCAGTCACCT AGGGC and reverse 5'-GGTGGGCAGTACGAACTCAA-3'; 
mTOR, forward 5'-GGTGGACGAGCTCTTTGTCA-3' and reverse 5'-AGGAGCCCTAACACTCGGAT-3'; Beclin-1, forward 5'-CTCTCGTCAAGGCGTCACTTC-3' and reverse 5'-CCTTAGACCCCTCCATTCCTCA-3'; GAPDH forward 5'-CTCCCATTCCRCCACCTTTG-3' and reverse 5'-CCA CCACCCTGTTGCTGAG-3'. The RT-qPCR procedure was performed as follows: Stage 1 and 2 (RT reaction) comprising one cycle at $42^{\circ} \mathrm{C}$ for $50 \mathrm{~min}$ and $95^{\circ} \mathrm{C}$ for $10 \mathrm{sec}$. Stage 3 (qPCR reaction) involving repetition of 45 cycles at $95^{\circ} \mathrm{C}$ for $15 \mathrm{sec}$ and $56^{\circ} \mathrm{C}$ for $20 \mathrm{sec}$. Stage 4 involved melting curve analysis following the dissociation protocol.

Water maze test. The laboratory animals were subjected to a water maze test at $48 \mathrm{~h}$ post-I/R. The escape platform was placed in the second quadrant of the water maze. The water level was $2-3 \mathrm{~cm}$ above the platform, and temperature was maintained at $25 \pm 1^{\circ} \mathrm{C}$. The rats were placed in a fixed position in the four quadrants, respectively. The time limit for swimming was $90 \mathrm{sec}$. The length of time a rat spent locating the platform was recorded. The length of time was recorded as $90 \mathrm{sec}$ if a rat failed to locate the platform within $90 \mathrm{sec}$. A water maze video tracking system (MED-SYST-VWM, MED Associates, Inc., Fairfax, VT, USA) were used to follow, image and analyze the route of a rat from the four quadrants to the platform, the latency and the number of times a rat crossed the platform.

Statistical analysis. A database of experimental data was established using Microsoft Excel 2003 (Microsoft Corporation, USA, Redmond, WA, USA). All data are expressed as the mean \pm standard error. SPSS 17.0 statistical analysis software (SPSS, Inc., Chicago, IL, USA) was used for one-way analysis of variance. $\mathrm{P}<0.05$ was considered to indicate a statistically significant difference.

\section{Results}

$H \& E$ staining. The nerve cells in the hippocampus of the SO group rats were neatly arranged and exhibited normal structures; nuclei were clear and the nucleoli were visible. Swelling of neurons was observed in the majority of the I/R group rats, with loose structures. The nuclei of these neurons were shrunken and darkly stained, with complete disappearance of nuclei in certain neurons and the formation of vacuole-like structures. In the OSAHS hypoxia groups, the morphology and structure of the nerve cells showed marked damage. A large number of nerve cells underwent necrosis, exhibiting loose structures. The nuclei of these neurons were shrunken and darkly stained, with complete disappearance of nuclei in certain neurons and the formation of vacuole-like structures. The damage to nerve cell morphology and structure was more severe in the $\mathrm{IH} 21+\mathrm{I} / \mathrm{R}$ group. Imaging analysis showed that, compared with the SO group, the survival rates of nerve cells were reduced in all $\mathrm{I} / \mathrm{R}$ groups $(\mathrm{P}<0.05)$. Compared with the $I / R$ group, the survival rates of nerve cells at each time point were reduced in both IH groups $(\mathrm{P}<0.05)$, however, these changes were more marked in the $\mathrm{IH} 21+\mathrm{I} / \mathrm{R}$ group. The results are shown in Table I and Fig. 1A-D.

Observation using transmission electron microscopy. In the SO group, the rat hippocampus nerve cells were in ordered
Table I. Comparison of survival rates of rat hippocampal nerve cells among treatment groups.

Survival rate of nerve cells $(\%)$

\begin{tabular}{lccl}
\cline { 3 - 4 } Group & Animals $(\mathrm{n})$ & $6 \mathrm{~h}$ & \multicolumn{1}{c}{$24 \mathrm{~h}$} \\
\hline SO & 5 & $99.08 \pm 0.84$ & $98.65 \pm 0.75$ \\
$\mathrm{I} / \mathrm{R}$ & 5 & $78.65 \pm 1.43^{\mathrm{a}}$ & $71.71 \pm 1.39^{\mathrm{a}}$ \\
$\mathrm{IH} 7+\mathrm{I} / \mathrm{R}$ & 5 & $65.742 \pm 1.20^{\mathrm{a}, \mathrm{b}}$ & $60.75 \pm 1.39^{\mathrm{a}, \mathrm{b}}$ \\
$\mathrm{IH} 21+\mathrm{I} / \mathrm{R}$ & 5 & $49.06 \pm 1.70^{\mathrm{a}-\mathrm{c}}$ & $45.12 \pm 1.51^{\mathrm{a}-\mathrm{c}}$ \\
\hline
\end{tabular}

Data are presented as the mean \pm standard error. ${ }^{\text {a }}<<0.05$, compared with the SO group; ${ }^{\mathrm{b}} \mathrm{P}<0.05$, compared with the I/R group; ${ }^{\mathrm{C}} \mathrm{P}<0.05$, compared with the IH7+I/R group. SO, sham operation; I/R, ischemia/reperfusion; IH7, intermittent hypoxia for 7 days; IH21, intermittent hypoxia for 21 days.

Table II. Comparisons of latency and times platform crossed among rats from each treatment group in the water maze test.

\begin{tabular}{lccc}
\hline Group & Animals (n) & $\begin{array}{c}\text { Latency } \\
\text { period }\end{array}$ & $\begin{array}{c}\text { Times platform } \\
\text { crossed (n) }\end{array}$ \\
\hline SO & 10 & $7.20 \pm 1.45$ & $12.47 \pm 0.92$ \\
I/R & 10 & $14.04 \pm 0.62^{\mathrm{a}}$ & $8.53 \pm 0.60^{\mathrm{a}}$ \\
$\mathrm{IH} 7+\mathrm{I} / \mathrm{R}$ & 10 & $17.23 \pm 0.89^{\mathrm{a}, \mathrm{b}}$ & $6.57 \pm 0.65^{\mathrm{a}, \mathrm{b}}$ \\
$\mathrm{IH} 21+\mathrm{I} / \mathrm{R}$ & 10 & $29.79 \pm 1.96^{\mathrm{a}-\mathrm{c}}$ & $1.15 \pm 0.33^{\mathrm{a}-\mathrm{c}}$ \\
\hline
\end{tabular}

Data are presented as the mean \pm standard error. ${ }^{a} \mathrm{P}<0.05$, compared with the SO group; ${ }^{\mathrm{b}} \mathrm{P}<0.05$, compared with the I/R group; ${ }^{\mathrm{C}}<0.05$, compared with the $\mathrm{IH} 7+\mathrm{I} / \mathrm{R}$ group. SO, sham operation; I/R, ischemia/reperfusion; IH7, intermittent hypoxia for 7 days; IH21, intermittent hypoxia for 21 days.

arrangement with a smooth nuclear membrane. Chromatin was evenly scattered in the nuclei. There were abundant organelles in the nerve cell cytoplasm, exhibiting normal structures. In the $\mathrm{I} / \mathrm{R}$ groups, the nuclear membrane of the rat hippocampus nerve cells was dissolved. Chromatin had shrunk in the nuclei. The number of nerve cell cytoplasmic organelles was reduced but with integrated structure. In the IH7+I/R group, the nuclei were stained on the edge and cytoplasmic organelles disappeared in neurons. In the IH21+I/R group, nuclear shrinkage was observed and nuclear chromatin was dissolved. Cytoplasmic organelles were reduced in the nerve cells, with obscure structures, as shown in Fig. 2A-D.

Water maze test. Compared with the rats in the SO group, the rats in the I/R group exhibited increased escape latency and decreased platform crossing $(\mathrm{P}<0.05)$. Compared with the I/R group, the rats in the OSAHS group exhibited increased escape latency and decreased platform crossing $(\mathrm{P}<0.05)$. Compared with the $\mathrm{IH} 7+\mathrm{I} / \mathrm{R}$ group, the rats from the $\mathrm{IH} 21+\mathrm{I} / \mathrm{R}$ group exhibited increased escape latency and decreased platform crossing $(\mathrm{P}<0.05)$. The results are shown in Table II. 
A

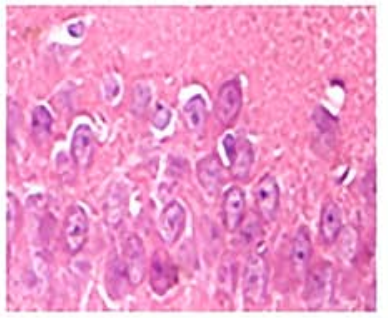

B

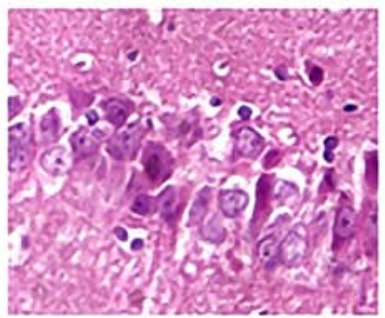

C

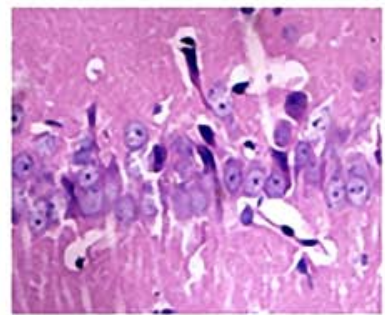

D

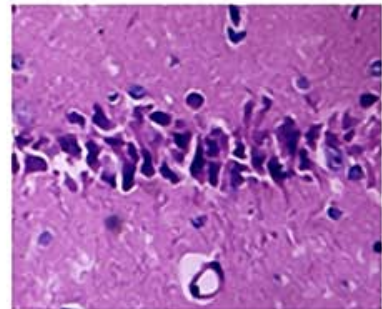

Figure 1. Rat hippocampal nerve cells $24 \mathrm{~h}$ following I/R in each group (H\&E staining; magnification, $\mathrm{x} 400$ ). (A) Sham operation; (B) I/R; (C) intermittent hypoxia for 7 days $+\mathrm{I} / \mathrm{R}$; (D) intermittent hypoxia for 21 days $+\mathrm{I} / \mathrm{R}$. I/R, ischemia/reperfusion.

A

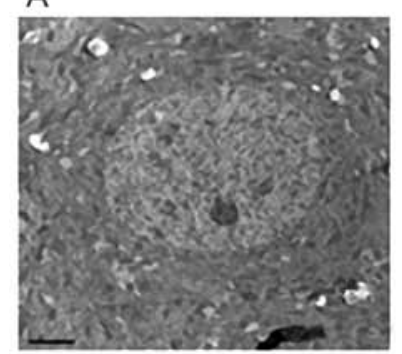

B

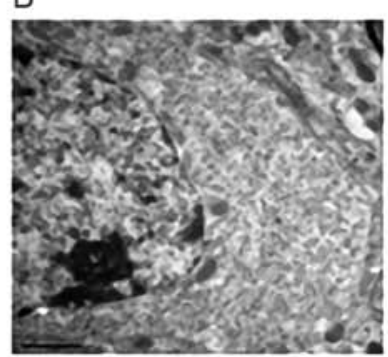

C

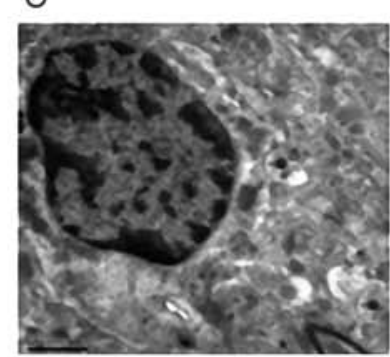

D

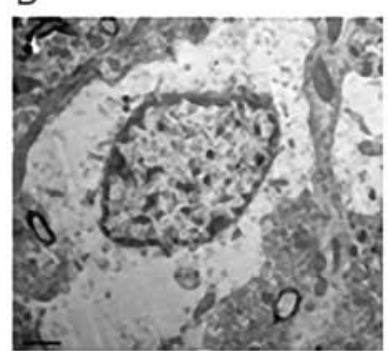

Figure 2. Morphological changes of rat hippocampus nerve cells $24 \mathrm{~h}$ following $\mathrm{I} / \mathrm{R}$ in each group (transmission electron microscope; magnification, $\mathrm{x} 20,000$ ). (A) Sham operation; (B) I/R; (C) intermittent hypoxia for 7 days + I/R; (D) intermittent hypoxia for 21 days + I/R. I/R, ischemia/reperfusion.
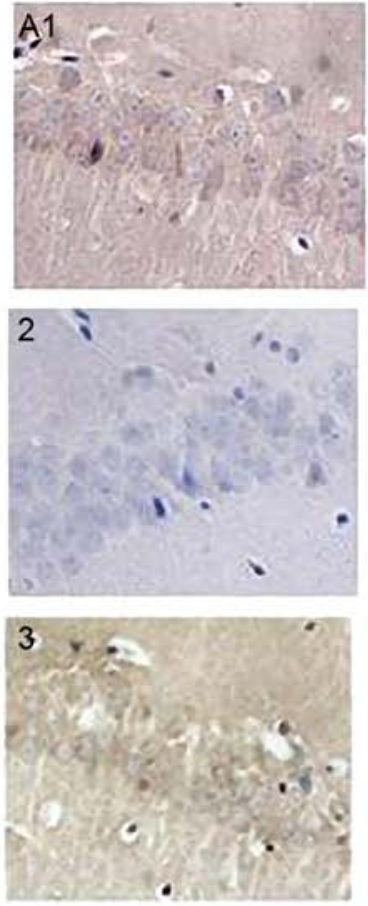
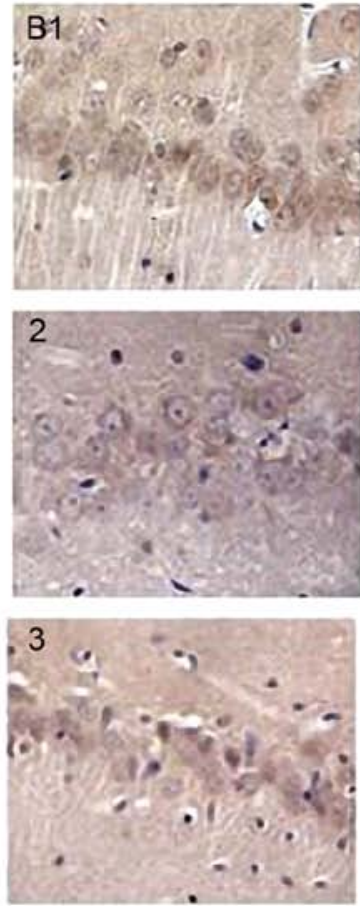
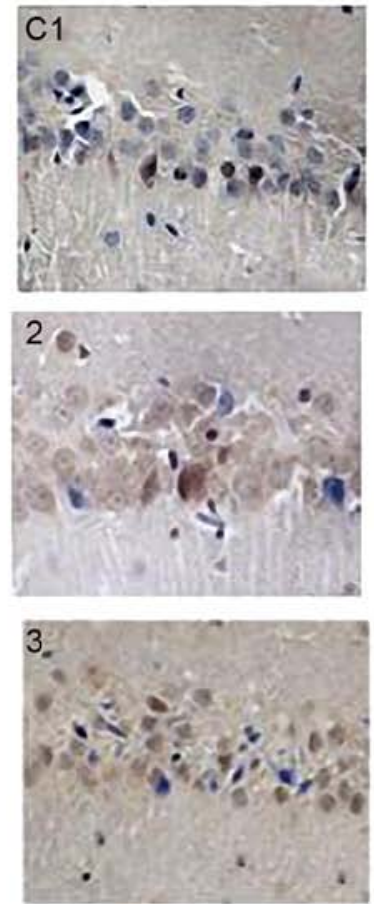
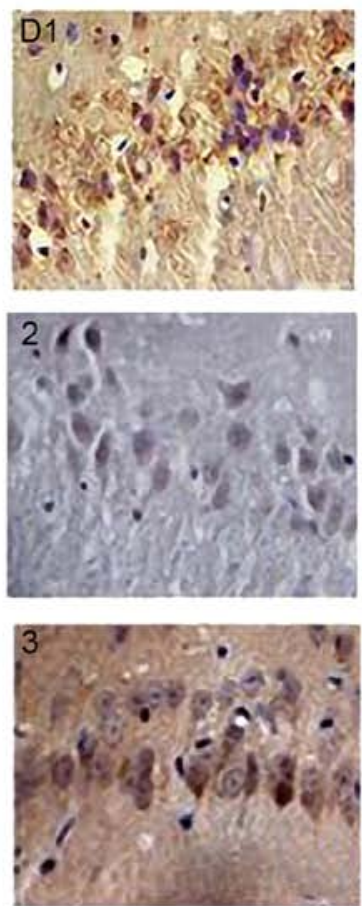

Figure 3. Positive expression of PI3K, mTOR and Beclin-1 $24 \mathrm{~h}$ following I/R in the rat hippocampus of each group (immunohistochemistry; magnification, $x 400$ ). (A1-D1) PI3K immunohistochemistry result in hippocampal tissues of the SO, I/R, IH7+I/R and IH21+I/R groups. (A2-D2) mTOR immunohistochemistry result in hippocampal tissues of the SO, I/R, IH7+I/R and IH21+I/R groups. (A3-D3) Beclin-1 immunohistochemistry result in hippocampal tissues of the SO, I/R, IH7+I/R and IH21+I/R groups. PI3K, phosphatidylinositol 3-kinase; mTOR, mammalian target of rapamycin; SO, sham operation; I/R, ischemia/reperfusion; IH7 intermittent hypoxia for 7 days; IH21, intermittent hypoxia for 21 days.

\section{Immunohistochemistry}

$P I 3 K$. The immunohistochemical staining showed that PI3K (brown) was located in the cytoplasm and predominantly expressed in neurons. Positively stained cells were occasionally observed in the SO group. At each time point $(6$ and $24 \mathrm{~h}$ ), the numbers of PI3K-positive cells were increased in the $\mathrm{I} / \mathrm{R}$ groups, compared with that in the $\mathrm{SO}$ group $(\mathrm{P}<0.05)$. At each time point ( 6 and $24 \mathrm{~h}$ ), the numbers of PI3K-positive 
Table III. PI3K-, mTOR- and Beclin-1-positive cells in the rat hippocampal tissues of each treatment group mean \pm SE, Cell/High Magnification Sight (x400).

\begin{tabular}{|c|c|c|c|c|c|c|c|}
\hline \multirow[b]{2}{*}{ Group } & \multirow[b]{2}{*}{$\mathrm{n}$} & \multicolumn{2}{|c|}{ PI3K } & \multicolumn{2}{|c|}{ mTOR } & \multicolumn{2}{|c|}{ Beclin-1 } \\
\hline & & $6 \mathrm{~h}$ & $24 \mathrm{~h}$ & $6 \mathrm{~h}$ & $24 \mathrm{~h}$ & $6 \mathrm{~h}$ & $24 \mathrm{~h}$ \\
\hline SO & 5 & $7.04 \pm 0.47$ & $10.79 \pm 0.70$ & $14.65 \pm 0.48$ & $15.40 \pm 0.58$ & $2.06 \pm 0.23$ & $2.10 \pm 0.30$ \\
\hline $\mathrm{I} / \mathrm{R}$ & 5 & $19.56 \pm 0.41^{\mathrm{a}}$ & $20.80 \pm 0.60^{\mathrm{a}}$ & $22.38 \pm 0.46^{\mathrm{a}}$ & $24.16 \pm 0.60^{\mathrm{a}}$ & $8.58 \pm 0.58^{\mathrm{a}}$ & $10.58 \pm 0.49^{a}$ \\
\hline $\mathrm{IH} 7+\mathrm{I} / \mathrm{R}$ & 5 & $23.05 \pm 0.58^{\mathrm{a}, \mathrm{b}}$ & $23.93 \pm 0.32^{\mathrm{a}, \mathrm{b}}$ & $25.31 \pm 0.39^{\mathrm{a}, \mathrm{b}}$ & $27.46 \pm 0.74^{\mathrm{a}, \mathrm{b}}$ & $11.12 \pm 0.35^{\mathrm{a}, \mathrm{b}}$ & $13.49 \pm 0.38^{\mathrm{a}, \mathrm{b}}$ \\
\hline $\mathrm{IH} 21+\mathrm{I} / \mathrm{R}$ & 5 & $25.62 \pm 0.41^{\mathrm{a}-\mathrm{c}}$ & $26.07 \pm 0.64^{\mathrm{a}-\mathrm{c}}$ & $30.40 \pm 0.43^{\mathrm{a}-\mathrm{c}}$ & $32.86 \pm 0.50^{\mathrm{a}-\mathrm{c}}$ & $15.57 \pm 0.57^{\mathrm{a}-\mathrm{c}}$ & $18.78 \pm 0.43^{\mathrm{a}-\mathrm{c}}$ \\
\hline
\end{tabular}

Data are presented as the mean \pm standard error $(\mathrm{SE}) .{ }^{\mathrm{a}} \mathrm{P}<0.05$, compared with the $\mathrm{SO}$ group; ${ }^{\mathrm{b}} \mathrm{P}<0.05$, compared with the $\mathrm{I} / \mathrm{R}$ group, ${ }^{\mathrm{c}} \mathrm{P}<0.05$, compared with the IH7+I/R group. PI3K, phosphatidylinositol 3-kinase; mTOR, mammalian target of rapamycin; SO, sham operation; $\mathrm{I} / \mathrm{R}$, ischemia/reperfusion; IH7, intermittent hypoxia for 7 days; IH21, intermittent hypoxia for 21 days.

Table IV. Changes in the relative mRNA expression of PI3Ka and mTOR in rat hippocampal tissues of treatment groups.

\begin{tabular}{|c|c|c|c|c|c|c|c|}
\hline \multirow[b]{2}{*}{ Group } & \multirow[b]{2}{*}{$\mathrm{n}$} & \multicolumn{2}{|c|}{ PI3K } & \multicolumn{2}{|c|}{ mTOR } & \multicolumn{2}{|c|}{ Beclin-1 } \\
\hline & & $6 \mathrm{~h}$ & $24 \mathrm{~h}$ & $6 \mathrm{~h}$ & $24 \mathrm{~h}$ & $6 \mathrm{~h}$ & $24 \mathrm{~h}$ \\
\hline $\mathrm{SO}$ & 5 & $1.00 \pm 0.00$ & $1.00 \pm 0.00$ & $1.00 \pm 0.00$ & $1.00 \pm 0.00$ & $1.00 \pm 0.00$ & $1.00 \pm 0.00$ \\
\hline $\mathrm{I} / \mathrm{R}$ & 5 & $1.38 \pm 0.06^{\mathrm{a}}$ & $1.43 \pm 0.07^{\mathrm{a}}$ & $1.22 \pm 0.10^{\mathrm{a}}$ & $1.27 \pm 0.08^{a}$ & $1.57 \pm 0.11^{\mathrm{a}}$ & $1.79 \pm 0.09^{a}$ \\
\hline $\mathrm{IH} 7+\mathrm{I} / \mathrm{R}$ & 5 & $1.63 \pm 0.09^{\mathrm{a}, \mathrm{b}}$ & $1.71 \pm 0.09^{\mathrm{a}, \mathrm{b}}$ & $1.53 \pm 0.06^{\mathrm{a}, \mathrm{b}}$ & $1.56 \pm 0.10^{\mathrm{a}, \mathrm{b}}$ & $1.98 \pm 0.15^{\mathrm{a}, \mathrm{b}}$ & $2.10 \pm 0.08^{\mathrm{a}, \mathrm{b}}$ \\
\hline $\mathrm{IH} 21+\mathrm{I} / \mathrm{R}$ & 5 & $2.18 \pm 0.07^{\mathrm{a}-\mathrm{c}}$ & $2.29 \pm 0.06^{\mathrm{a}-\mathrm{c}}$ & $1.65 \pm 0.06^{\mathrm{a}-\mathrm{c}}$ & $1.73 \pm 0.07^{\mathrm{a}-\mathrm{c}}$ & $2.37 \pm 0.14^{\mathrm{a}-\mathrm{c}}$ & $2.54 \pm 0.24^{\mathrm{a}-\mathrm{c}}$ \\
\hline
\end{tabular}

Data are presented as the mean \pm standard error. ${ }^{\mathrm{a}} \mathrm{P}<0.05$, compared with the $\mathrm{SO}$ group; ${ }^{\mathrm{b}} \mathrm{P}<0.05$, compared with the $\mathrm{I} / \mathrm{R}$ group; ${ }^{\mathrm{c}} \mathrm{P}<0.05$, compared with the IH7+I/R group. PI3K, phosphatidylinositol 3-kinase; mTOR, mammalian target of rapamycin; SO, sham operation; $\mathrm{I} / \mathrm{R}$, ischemia/reperfusion; IH7, intermittent hypoxia for 7 days; IH21, intermittent hypoxia for 21 days.

cells were increased in the IH groups, compared with that in the $\mathrm{I} / \mathrm{R}$ group $(\mathrm{P}<0.05)$. These changes were more marked in the $\mathrm{IH} 21+\mathrm{I} / \mathrm{R}$ group $(\mathrm{P}<0.05)$, as shown in Table III and Fig. 3A1-D1.

mTOR. The imunohistochemical staining showed that mTOR (brown) was located in the cytoplasm and predominantly expressed in neurons. Positively stained cells were occasionally observed in the SO group. At each time point (6 and $24 \mathrm{~h}$ ), the numbers of mTOR-positive cells were increased in the $\mathrm{I} / \mathrm{R}$ groups, compared with that in the $\mathrm{SO}$ group $(\mathrm{P}<0.05)$. At each time point (6 and $24 \mathrm{~h})$, the numbers of mTOR-positive cells were increased in the IH groups, compared with that in the $I / R$ group $(\mathrm{P}<0.05)$. These changes were more marked in the IH $21+\mathrm{I} / \mathrm{R}$ group $(\mathrm{P}<0.05)$, as shown in Table III and Fig. 3A2-D2.

Beclin-1. The immunohistochemical staining showed that Beclin-1 (brown) was located in the cytoplasm and predominantly expressed in neurons. Positively stained cells were occasionally observed in the SO group. At each time point (6 and $24 \mathrm{~h}$ ), the numbers of Beclin-1-positive cells were increased in the $\mathrm{I} / \mathrm{R}$ groups, compared with that in the SO group $(\mathrm{P}<0.05)$. At each time point $(6$ and $24 \mathrm{~h})$, the numbers of Beclin-1-positive cells were increased in the $\mathrm{IH}$ groups, compared with that in the $\mathrm{I} / \mathrm{R}$ group $(\mathrm{P}<0.05)$. These changes were more marked in the $\mathrm{IH} 21+\mathrm{I} / \mathrm{R}$ group $(\mathrm{P}<0.05)$, as shown in Table III and Fig. 3A3-D3.

\section{RT-qPCR analysis}

$P I 3 K$. At each time point ( 6 and $24 \mathrm{~h}$ ), the expression of PI3K was significantly increased in the I/R group, compared with that in the SO group $(\mathrm{P}<0.05)$. At each time point $(6$ and $24 \mathrm{~h})$, the expression of PI3K was significantly increased in the IH groups, compared with that in the I/R group $(\mathrm{P}<0.05)$. These changes were more marked in the IH21+I/R group, as shown in Table IV.

mTOR. At each time point (6 and $24 \mathrm{~h}$ ), the expression of mTOR was significantly increased in the I/R group, compared with that in the SO group $(\mathrm{P}<0.05)$. At each time point (6 and $24 \mathrm{~h}$ ), the expression of mTOR was significantly increased in the IH groups, compared with that in the I/R group $(\mathrm{P}<0.05)$. These changes were more marked in the IH $21+\mathrm{I} / \mathrm{R}$ group, as shown in Table IV.

\section{Discussion}

In addition to being a respiratory disease, OSAHS is able to damage and involve multiple systems, leading to damage in the brain, heart and other organs, and to the neurological system in particular (9). Studies have shown that, due to repeated hypoxia and hypercapnia, OSAHS can cause cerebral blood rheology, 
cerebral metabolic change, dysfunction of neurohumoral regulation, oxidative stress and inflammation, initiating and aggravating the pathophysiological progress of cerebral I/R (10). This leads to neuron loss, and damage to the morphology and structure of nerve cells in multiple cerebral regions, thereby increasing nerve damage following cerebral I/R (11). The neurological dysfunction following brain ischemia is directly associated with the loss of nerve cells. For example, the results of a study by Sun et al (12) showed that the number of viable nerve cells was reduced and learning ability was decreased following brain I/R. Running exercise increased the survival rate of nerve cells and improved learning ability in rats. The results of the present study showed that, compared with the I/R group, rats in each OSAHS hypoxia group exhibited reduced nerve cell survival in the hippocampus, severely damaged nerve cell structure, and apparent dysfunction in learning and memory ability. This indicated that OSAHS hypoxia aggravated rat neurological damage following brain $\mathrm{I} / \mathrm{R}$, and these results were consistent with those of clinical studies $(13,14)$.

Autophagy is a process, which is extensively present in eukaryotic organisms and functions through the lysosomal pathway, which involves the identification, degradation and reversal of functionally damaged proteins and organelles with physiological and pathological factors. It is a third mechanism of cellular death in addition to apoptosis and necrosis (15). Wang et al (16) established rat whole brain ischemia models and observed nerve cells in the CA1 hippocampal region. It was found that damage to neurons induced by whole brain ischemia was significantly reduced following the addition of autophagy inhibitor 3-MA at $1 \mathrm{~h}$ or $30 \mathrm{~min}$ prior to ischemia. This indicated that ischemia-induced autophagy aggravated neuron damage led by brain ischemia. The results of the present study showed that, compared with the I/R group, the rats in the IH groups exhibited aggravated damage in neuron structure, reduced neuron survival rates and increased expression of Beclin-1. These changes were more marked in the $\mathrm{IH} 21+\mathrm{I} / \mathrm{R}$ group, indicating that autophagy in the process of $\mathrm{I} / \mathrm{R}$ alone was further activated by $\mathrm{IH}$ to promote neuron loss following brain ischemia. IH can facilitate the activation of autophagy. For example, Liu et al (17) established mouse IH models and observed autophagy-associated protein expression in nerve cells of the mouse hippocampal CA1 region following IH. The results showed that the protein levels of LC3II/LC3 were increased and damage to the microstructure of nerve cells was aggravated, indicating that $\mathrm{IH}$ induced autophagy in the rat hippocampal nerve cells.

The activation of autophagy is dependent on the $\mathrm{PI} 3 \mathrm{~K} / \mathrm{Akt} / \mathrm{mTOR}$ signaling pathway (18). It has been shown that the activities of PI3K, Akt and mTOR are significantly increased following brain ischemia. Ishrat et al (19) prepared rat focal brain ischemia models by cerebral artery occlusion and observed significantly elevated phosphorylation levels of PI3K and Akt in addition to nerve cell apoptosis, indicating that brain ischemia activated the PI3K/Akt signaling pathway. Zhao et al (20) exposed rats with chronic brain ischemia to flavonoids from hawthorn leaves, and detected the protein expression levels of PI3K and Akt using immunohistochemistry. The results showed that flavonoids from hawthorn leaves increased the protein expression of PI3K and $\mathrm{Akt}$, and reduced brain tissue damage. It has been reported that (21) under ischemia and hypoxic conditions, the cellular $\mathrm{PI}$ KK/Akt signaling pathway is activated and autophagy can be induced by regulating the activity of mTOR. The results from a study by Liu and Xu (22) demonstrated that sevoflurane pre-treatment reduced the autophagy of cardiac muscle cells during I/R through activating the PI3K/Akt signaling pathway and enhancing downstream mTOR activity, which had a protective effect on cardiac muscles. Gong et al (23) established focal brain ischemia models in Sprague-Dawley rats and found that the PI3K inhibitor, LY294002, inhibited the PI3K-mTOR signaling pathway and subsequently inhibited autophagy, increasing the area of infarction in rats. The results of the present study showed that the expression levels of PI3K and mTOR were elevated in all the IH groups, and this was associated with the degree of hypoxia. This indicated that $\mathrm{IH}$ increased autophagy and aggravated neurological dysfunction following cerebral ischemia by activating the PI3K/Akt/mTOR signaling pathway. At present, the mechanisms underlying the regulation of PI3K/Akt /mTOR signaling by IH remain to be fully elucidated. However, it has been shown that the characteristic chronic IH hypoxia in OSAHS, similar to damage from I/R, aggravates hypoxia, and induces oxygen free radical production, ATP depletion and inflammation (24), which may be one of the reasons why the PI3K/Akt signaling pathway was activated by $\mathrm{IH}$ following cerebral ischemia.

In conclusion, the present study demonstrated that $\mathrm{IH}$ promoted autophagy and aggravated neurological dysfunction following brain ischemia through regulating the $\mathrm{PI} 3 \mathrm{~K} / \mathrm{Akt} / \mathrm{mTOR}$ cascade signaling pathway. These results provided experimental evidence for the prevention and treatment of OSAHS-complicated brain ischemia.

\section{Acknowledgements}

Not applicable.

\section{Funding}

This study was supported by the Health Department of Hebei Province Key Project and Leading Talent Project (grant no. zd2013087) and the Tangshan City Science and Technology Project (grant no. 14130220B).

\section{Availability of data and materials}

All data generated and/or analyzed during the present study are included in this published article.

\section{Authors' contributions}

XG conceived the present study. YNZ made substantial contributions in data analysis and wrote the manuscript. YL and RF performed the experiments. YLB, XFG, JML and CXC designed the study. All authors read and approved the final manuscript.

\section{Ethics approval and consent to participate}

The Animal Experimentation Ethics Committee of North China University of Science and Technology (Hebei, China) 
approved the experimental animal protocol of the present study.

\section{Patient consent for publication}

Not applicable.

\section{Competing interests}

The authors declare that they have no competing interests.

\section{References}

1. Deng XZ,Liu B and Li Y: Research progress of obstructive sleep apnea hyponea syndrome and hypertension. Adv Cardiovasc Dis 35: 230-233, 2014 (In Chinese).

2. Cho ER, Kim H, Seo HS, Suh S, Lee SK and Shin C: Obstructive sleep apnea as a risk factor for silent cerebral infarction. J Sleep Res 22: 452-458, 2013.

3. Wang Z, Zhao YN and Li JM: Effects of grape seed proanthocyanidin extract on peroxidation and ability of learning and memory after cerebral ischemia/re-perfusion injury in rats. Chin J Rehabil Theory Pract 20: 827-830, 2014 (In Chinese).

4. Tang YA: Study on cognitive impairment and mechanism causing by chronic cerebral hypoperfusion in rats. Sichuan Med J 31: 1226-1228, 2010 (In Chinese).

5. Wang WY, Cui ZR and Jiang W: Autophagy in research progress in the role of brain ischemia-reperfusion injury. J Shanghai Jiaotong Univ 34: 248-253, 2014 (In Chinese).

6. Sami A and Karsy M: Targeting the PI3K/AKT/mTOR signaling pathway in glioblastoma: Novel therapeutic agents and advances in understanding. Tumour Biol 34: 1991-2002, 2013.

7. Jeong EH, Choi HS, Lee TG, Kim HR and Kim CH: Dual inhibition of PI3K/Akt/mTOR pathway and role of autophagy in non-small cell lung cancer cells. Tuberc Respir Dis (Seoul) 72 : 343-351, 2012.

8. Bin Y, Yu LJ, Wang J, Zhao L, Hu XY, Ji CN, Wei YL, Yang QF, Jiang QS, Yang JQ et al: Time course change of PGI2 and TA2 levels in rat cortex following global cerebral ischemia reperfusion. Chin Pharmacol Bull 29: 1667-1671, 2013 (In Chinese).

9. Capampangan DJ, Wellik KE, Parish JM, Aguilar MI, Snyder CR, Wingerchuk D and Demaerschalk BM: Is obstructive sleep apnea an independent risk factor for stroke? A critically appraised topic. Neurologist 16: 269-273, 2010.

10. Guo X, Zhao Y, Li J, Liu W and Chen C: Activation of autophagy pathway in hippocampus and deterioration of learning and memory ability by intermittent hypoxia in rats after cerebral ischemia. Xi Bao Yu Fen Zi Mian Yi Xue Za Zhi 32: 1212-1216, 2016 (In Chinese).
11. Yang D and Liu ZH: Exploring the relationship and pathogenesis between obstructive sleep apnea and cardiovascular diseases. Adv Cardiovasc Dis 32: 645-648, 2011 (In Chinese).

12. Sun ZM, Zhao YN, Li JM, Chen CX, Zhao X and Chen NL: Effect of intensity of exercise on learning ability and oxygen free radical metabolism in rats after cerebral ischemia-reperfu-sion. Chin J Rehabil Theory Pract 21: 26-30, 2015 (In Chinese).

13. Lu WL, Guo Y, Li DX and Zhang S: Effects of obstructive sleep apnea syndrome on cognitive function in ischemic stroke patients. Chinese Community Doctors, 30: 26-27, 2014 (In Chinese).

14. Mansukhani MP, Bellolio MF, Kolla BP, Enduri S, Somers VK and Stead LG: Worse outcome after stroke in patients with obstructive sleep apnea: An observational cohort study. J Stroke Cerebrovasc Dis 20: 401-405, 2011.

15. Ding H, Tang YH and Huang XP: Effects of autophagy in cerebral ischemic injury. Chin Pharmacol Bull 31: 1048-1052, 2015 (In Chinese).

16. Wang JY, Xia Q, Chu KT, Pan J, Sun LN, Zeng B, Zhu YJ, Wang Q, Wang K and Luo BY: Severe global cerebral ischemia-induced programmed necrosis of hippocampal CA1 neurons in $\mathrm{mt}$ is prevented by 3-Methyladenine: A widely used inhibitor of autophagy. J Neuropathol Exp Neurol 70: 314-322, 2011.

17. Liu HY, Chen R, Li YN, Zhang YL and Liu CF. Chronic intermittent hypoxia area in mice hippocampal CAl neurons autophagy. Chin J Tuberc Respir Dis. 34: 467-469, 2011 (In Chinese).

18. Wu MM, Wan RH and Chen NH: Research progress on the mTOR signaling pathway and neurodegenerative disease. Chin Pharmacol Bull 27: 1481-1483, 2011 (In Chinese).

19. Ishrat T, Sayeed I, Atif F, Hua F and Stein DG: Progesterone is neuroprotective against ischemic brain injury through its effects on the phosphoinositide 3-kinase/protein kinase B signaling pathway. Neuroscience 210: 442-450, 2012.

20. Zhao L, Zhang XH, Wu BC, et al: Hawthorn leaves flavonoids on cerebral ischemia rats organization PI3K/Akt signal pathway. Guangdong Med J 35: 982-984, 2014 (In Chinese).

21. Sengupta S, Peterson TR and Sabatini DM: Regulation of the mTOR complex 1 pathway by nutrients, growth factors, and stress. Mol Cell 40: 310-322, 2010.

22. Liu L and Xu PC: Sevoflurane pretreatment of rats in vitro cardiac ischemia-reperfusion injury when autophagy and the effect of PI3K/Akt signaling pathway in the role. Chin J Anesthesiol 34: 492-496, 2014.

23. Gong L, Wang Z, Xing YG, et al: Effects of ischemic postconditioning on apoptosis in cerebral ischemia-reperfusion injury in rats and its mechanisms. J Int Neurol Neurosurg 39: 229-234, 2012.

24. Yang ML and Cai RW: Inflammatory reaction in obstructive sleep apnea syndrome and ischemic strok. Med Recapitul 16: 919-921, 2010. 